\title{
BUILDING “CODE”: DEVELOPMENT, MAINTENANCE, AND CHANGE IN A PRIVATE LANGUAGE
}

\author{
CHARLEY ROWE \\ University of Hong Kong
}

ABSTRACT: Using primarily data collected from the discussions of two sisters over a four-month period, this article shows the development and maintenance of private language orally and in the e-mail medium. Specifically, I demonstrate how a family private language first developed orally, then rapidly expanded into a special sibling code in the e-mail environment. The results have implications for the communicative potential in interpersonal interaction, particularly in terms of how interpersonal interaction can directly affect the rapidity of language change.

\section{BACKGROUND: THE NATURE OF E-MAIL AND ITS CAPACITY AS A VESSEL FOR CHANGE}

In order to contemplate how change can emerge and stabilize in a certain domain (in this case, e-mail), it will be necessary to discuss the features of the domain which can help to foster change. In this regard, I will briefly examine the physical (technical) and psychological features of e-mail which together can foment linguistic change.

E-MAIL AND E-MAIL SOFTWARE HAVE CERTAIN PHYSICAL FEATURES WHICH MAY SUPPORT LANGUAGE CHANGE. Notably, e-mail allows for text "visibility." Because e-mail has greater lag time between responses than spoken language, users' memories may be taxed in the time between message sending, receipt, and reply in an exchange. Fortunately, e-mail provides a convenient conversational tool not available in spoken language-namely, the "include previous message" or "quoting" feature available in most e-mail software. This feature allows the respondent the option of including the previous message in the response, in order to help the conversant to keep up with the flow of the conversation. If both participants use the feature without exception, the entire message history is included in each mailing. The result of this "text visibility" is that the e-mail exchange is relatively conversational, providing the "memory" aspect to compensate for the lack of immediacy. ${ }^{1}$

American Speech, Vol. 82, No. 3, Fall 2007 DOI $10.1215 / 0003128$ 3-2007-011

Copyright 2007 by the American Dialect Society 
E-mail, as a hybrid of written and oral language, also allows for high levels of interactivity and editability (Ferrara, Brunner, and Whittemore 1991). Oral conversations, while typically highly interactive, are difficult for speakers to self-edit; speakers must either plan carefully or backtrack, neither of which allows much room for quick-wittedness. Likewise, with synchronous computer-mediated communication (such as Internet Relay Chat and Instant Messaging), lag time is so limited as to make editing unwieldy. ${ }^{2}$ Although we can easily edit written texts in conventionally written or typed letters, the lag time is usually somewhat long, resulting in decreased interactivity. E-mail, however, allows, relative to conventional written modes, a fairly quick turnaround time, providing an ideal opportunity to interact fairly rapidly (within minutes or even seconds) while still allowing for editability (thus promoting creativity). This makes for a combination of features that constitutes an exceptionally ripe environment for language play and, potentially, change.

Thus, it stands to reason that when conversants avail themselves of all of these e-mail features to their fullest (namely, a visible and persistent record of the previous message; text editability; and the optimization of the tension between lag time and speedy turnaround), the potential for metalinguistic awareness (see Cazden 1976) is heightened. Metalinguistic awareness creates a ripe environment for language play; indeed, such linguistic self-consciousness is the prerequisite for language play. The effect should be especially heightened when the participants already have a history of language play with each other, as do the sisters in the present study.

E-MAIL HAS CERTAIN PSYCHOLOGICAL FEATURES THAT MAY HELP FOSTER LANGUAGE CHANGE. As a relatively new written medium, e-mail has few prior conventions. Though there appears to be some indication of stylistic conventionalization, the newness of the medium (respective to other written media) still appears to harbor a fluctuation in norms. Ferrara, Brunner, and Whittemore $(1991,10)$ suggest that because computer-mediated communication is generally unnormed, users' styles are "acquired during use from other users." It is logical, then, as Cho (1996) notes for e-mail, that without strong norms, "idiostyles" pervade. More generally, new linguistic situations call for new registers (Ferrara, Brunner, and Whittemore 1991), and it is not surprising that speakers in new environments may converse more, expand their linguistic repertoire, and invent new elements of linguistic ritual (Danielewicz, Rogers, and Noblit 1996). This stylistic "loosening" can feed creativity: without the restraint of conventions, e-mail users are more free to play with language. ${ }^{3}$

Furthermore, because e-mail, unlike oral conversation, does not guarantee feedback, many users demand (or at least expect) humor from their 
more intimate or familiar conversants in order to keep the exchange lively; this practice may in turn promote lengthy or frequent exchanges (see also Rowe 2001). That is, as long as users can be kept entertained, the more willing and likely they are to keep up and even enhance their participation. ${ }^{4}$ This means that when it is used as a venue for humor or for linguistic performance, e-mail can have the additional effect of creating in-group solidarity (Baym 1995). When the sisters in the present study discover that they can "bond" over e-mail using humorous renditions of a family code, the frequency, duration, and level of creativity of their conversations increase dramatically. Importantly, the introduction of e-mail interaction appears to have been the only change in the environment that triggered this increase. But even in tandem, the physical and psychological features of the medium alone could not likely result in a sibling code of the type to be presented here. Rather, the nature of private language, which in the present case was staged in the e-mail environment, must be considered as well.

\section{THE NATURE OF PRIVATE LANGUAGES}

Special lects shared between intimates-that is, private languages-are a little-studied phenomenon. ${ }^{5}$ Though linguists, sociologists, and psychologists speak of the "intimate register," this refers primarily to casual speech among close familiars and makes no reference to any resultant specialty lects per se. Certainly dialogic communication in the "intimate register" (as well as the "casual/familiar register") has circumstances, domains, and features that lay the groundwork for potentially emergent private languages:

Dialogic speech is distinguished not only by the common code of two juxtaposed utterances, but also by the presence of a common memory shared by addresser and addressee. The absence of this factor makes a text undecipherable. In this respect it could be suggested that any text is characterized not only by code and message, but also by orientation toward a particular type of memory... From this point of view, two types of speech activity can be distinguished. The one is directed toward an abstract addressee the extent of whose memory is reconstructed by the addresser as typical of anyone speaking the given language. The other is directed to an actual interlocutor whom the speaker sees or with whom the writer is personally acquainted and the extent of whose memory is perfectly well known to the addresser. [Lotman $1982,81-82]$

However, this conception is not sufficiently detailed to describe the nature of private languages. An adequate description of the bases of private languages and their development can best be derived from three general concepts: that 
between persons who are psychologically close, (1) shared cultural knowledge and shared context are assumed (Voloshinov 1976, 100-101; Sebeok 1991, 30), (2) communication via "abbreviated" (Vygotsky 1986, 238) speech with “'domestic' and 'intimate' lexis”(Lotman 1982, 83; 1990, 64) is the norm, and (3) the resulting communication can be characterized by conglomerate word senses (Vygotsky 1986, 247) or other expressions that are essentially incomprehensible to the outside world (Vygotsky 1986, 247; Lotman 1982,$83 ; 1990,64)$.

In terms of the first and second concepts, intimate speech can, in the family context, recall earlier, especially childhood, experiences, which can extend prior speech events into present conversations. ${ }^{8}$ These build much of the shared cultural knowledge assumed and indeed should, in the family context, assume a relatively extensive breadth and depth of shared culture. This type of experience should, by its very nature (as just described), provide a ripe environment for private languages to emerge.

In terms of the third concept, a word may, in the intimate (and thus particularly familial) context, be imbued with a conglomerate of senses, all based in widely varying experiences and multiple contextual references. Thus, between persons in a close psychological relationship, words acquire senses that are grasped only by the individuals involved, such that an original idiom (a private or intimate language) is created (Vygotsky 1986, 248). These three concepts in tandem appear to constitute the necessary and sufficient essence of private languages.

The present article concerns itself precisely with a subset of private language even less studied than private language or family language itself, namely sibling private language. I will identify sibling private language as a subset of family private language, which, in turn, can be defined as any variety private to and specific to any certain family. ${ }^{9}$ In what follows, I examine a case study from a sister pair. On these and theoretical bases, I will draw conclusions about the nature of private speech (in particular, of family and sibling private languages) and the potential for intravariety language change, in particular, the potential of private languages to attain structural robustness.

In order for private languages to become robust, metalingual activity must be heightened. As with most forms of deliberated, planned linguistic activity (such as humor, imitation and parody, wordplay, poetry, etc.), some form of self-conscious linguistic analysis is involved. Often these have their basis in linguistic rituals which can be further mutated via context "triggers" and metaphorical extensions.

Sometimes, metalingual activity is largely a function of the medium (high metalingual activity being associated with the written medium in particular). As a medium which still largely retains its "fun" nature, e-mail may encourage some users to play with language, when they may not have done so in hard- 
copy personal letters that have been handwritten or even typed. This may be the result of both the physical (technical) and the psychological features of the e-mail medium, as just described. When this particular type of metalingual activity is combined with the other conditions for private language formation, a fairly robust variety may emerge and evolve.

\section{SISTERS' CODE: OVERVIEW AND DEVELOPMENT}

The sisters' code primary data consist of two adult sisters' e-mail communication, specifically, 245 e-mail messages logged between January 26, 1996 , and May 26, 1996, by the younger sister S2, who habitually logs personal e-mails. During these four months of their correspondence, the sisters were not aware that their e-mails would be of linguistic interest or that they would be used as data in this or any study (consent was granted after the fact). ${ }^{10}$ The average length of the messages was about 12 lines, or approximately one-quarter of a printed page.

The nature of the code's development is crucial: The first stage of this code emerged in the 1960 s when the younger sister imitated their father's idiolect and regional variety in parodied form for ironic effect. The rest of the family (the sisters' mother and the older sister) adopted the code in similar fashion, using the code primarily to "quote" the father. At some point soon thereafter, the father began to "quote" himself, using the parodied code. Other features of mixed origin also presented themselves as early family group codes-other language parodies that included parodies of the regional varieties of other relatives, "Archie Bunker" variants (from the popular 1970 os television series All in the Family), African American Vernacular English, and other linguistic renditions that reflected family "bonding." Some zo years later, the sisters communicated for three months by fax, during which family group code elements were restricted to opening and closing greetings. After they began communicating over e-mail, the individual family code elements immediately began to co-occur and became part of one code, the Sibling Code (SC). The SC then, over four months time, began to mutate, following patterns of conventionalization normally seen only in very longterm language change.

\section{BACKGROUND}

The father of the two sisters in the study is the source of the original code. He is Caucasian and speaks a regional variety of Southern English characteristic of his hometown Morrowton (pseudonym) in the coastal plains of North 
Carolina, about $15^{\circ}$ miles from where the sisters were raised. Morrowton's population was 27,000 around $195^{\circ}$. The father was 63 at the time of the data collection.

The mother of the sisters is Caucasian and was also born and raised in Morrowton. She speaks a characteristically upper-middle-class local version of the regional variety; accordingly, she invokes the salient features of $r$-lessness and some initial position voiced-for-voiceless $(t \rightarrow d)$ substitution (e.g., [dəme ${ }^{\mathrm{I}} \mathrm{r}$ ] 'tomato') characteristic of Morrowton.

The older sister (S1) was born in eastern North Carolina but moved with her parents to western North Carolina during her early childhood; she was 42 years old at the time of data collection. Her speech is best described as acrolectal western North Carolinian. The younger sister (S2) was born in western North Carolina, where she also was raised; she was 34 years old at the time of data collection. Her speech is also best described as acrolectal western North Carolinian, the same variety that her sister speaks. Both sisters have college degrees. S1 holds a professional position at a high administrative level of a public agency; S2 holds a medical research position at a postsecondary institution. There are eight years age difference between the two sisters, and there are no other siblings. The sisters now, as at the time of data collection, work 30 miles apart and live approximately 150 miles from each other.

Although the family relocated to western North Carolina when the parents were in their twenties, the parents' speech, in particular the father's speech, is still strongly characteristic of Morrowton and of his lower socioeconomic status. ${ }^{11}$ His speech pattern is also marked with certain idiosyncratic and regional discourse markers and other special expressions. Because he was raised in a markedly different linguistic environment, father's regional variety differs sharply from that of the two sisters, a situation which provided a ripe opportunity for $\mathrm{S} 2$, the younger sister, to create a "dialect caricature." Throughout this paper, I refer to the father's speech pattern as the Father Code (FC).

\section{THE ORAL PERIOD: THE FATHER CODE AND THE FAMILY GROUP CODE}

The father is the originator of the FC, which reflects his regional and individual speech characteristics, including initial stop-for-fricative substitution $(\theta \rightarrow t, \partial \rightarrow d)$ as well as the voiced-for-voiceless $(t \rightarrow d)$ substitution shared by the mother. The father, like many of his relatives, was raised in or around the Morrowton community; the FC does not reflect any significant outside influence aside from the community and family he grew up in. In charting 
the code's development (table 1), I refer to the father's original speech as stage I. I have placed audience members within parentheses.

When the father married the mother and had children (the sisters in the study), he became the minority gender in the family. He lightheartedly refers to himself as "overruled" by the others in the family, all women. Possibly because of the father's "overruled" status, and apparently in open rebellion against her father, S2 began to parody her father's lect, the FC, in jest when she was approximately eight years old, in the context of being disciplined. Typically, the father's pet phrases in the context of discipline provided the fodder for the parody. S2's parody of the FC is stage IIa in the development of the code.

S2's older sister and mother eventually began to parody the FC along with her. ${ }^{12}$ According to S2, S1 and the mother's parodies reflected S2's rendition, with no modifications. This is stage IIb.

Soon thereafter, the father himself began to parody the others' rendition of him. When he did, he made some minor modifications by exaggerating the parodied features of his idiolect that S2 had parodied. This is stage IIIa.

Soon the two sisters began to join in on the stage IIIa code, making no modifications, but adhering to the father's new variants. This was stage IIIb. The mother typically remained at stage IIb, while the sisters and father usually used the stage III code.

TABLE 1

Developmental Stages of the Sisters' Sibling Code

\begin{tabular}{llc}
\hline Participants & Speech Type & Stage \\
Father (S2, S1, mother) & Original individual version of regional & I \\
& variety (father); Father Code (FC) & \\
S2 (father, S1, mother) & Parody of father's speech & IIa \\
S2, S1, mother (father) & Parody of father's speech based on & IIb \\
Father (S1, S2, mother) & S2's parody & \\
S2, S1, father & Parody of S2's parody of father & IIIa \\
& Sarody of father's parody based on & IIIb \\
S1, S2, father, mother & IIb and IIIb code, plus external features & IV \\
& (from TV characters, friends, extended & \\
& family, etc.); Family Group Code (FamC), & \\
S2, S1 (in e-mail context) & Family group code in e-mail context plus & V \\
& additional modifications = E-mail & \\
& Sibling Code (SC) &
\end{tabular}


The family eventually began to weave other "campy" variants into the stage II/III code that reflected events that the family had shared together: phonology and phrases from the Archie Bunker character, variants from a family friend's performance code, and variants from relatives living in Morrowton.

The added "bonding" variants made the code structurally more complex. For example, there are lexical items with /orC/ that are borrowed from the local Queens variety used by the character Archie Bunker (e.g., hoit 'hurt', hoid 'heard', woik 'work', woid 'word'). Other Archie Bunker variants intersect with the $\mathrm{\partial} \rightarrow \mathrm{d}$ of the FC (e.g., the function words and articles $d a$, dat, dis, deze, doze, dere, din). Lexemes with final /or/ are associated with an aunt living in Morrowton (e.g., thaya 'there', prepaya 'prepare', etc.); words with /orC/ are associated with a cousin in Morrowton (mawnin 'morning', bawn 'born', gawgeous 'gorgeous', etc.). A pet phrase (dot's troo) intrudes from a family friend's performance code ${ }^{13}$ its initial $\mathrm{\partial} \rightarrow \mathrm{d}$ (dot 'that', dere, din, da, etc.), as with the Archie Bunker variants, intersects with the already formed FC.

The family code is contextually restricted to: (a) the context of dogmatism (when the father or mother attempts to assert authority with the sisters); (b) the context of preemptive quoting (when one of the sisters preempted the parents' assertions or objections in the context of a family argument); and (c) the context of narration in which the father is the main character. All three are examples of performance and parody. The use of the stage II or stage III code with added family "bonding" variants occupies stage IV in the development, and is what I collectively refer to as the Family Group Code (FamC).

The two sisters estimate that the FamC had comprised about $10 \%$ of their spoken communication with each other prior to their interaction over e-mail. According to S2, the FamC was used largely in certain phrases of the FC:

1. Family Group Code

Ya playans been chainged, sistah 'Your plans have been changed, young lady!' I can't beleeb dat 'I can't believe that!'

I mane dat tang 'I'm serious about that!; lit. I mean that thing!'

I'll tell ya one tang right now 'I promise; lit. I'll tell you one thing right now!' (warning)

Whatcha nade? 'What's up?; lit. What do you need?'

The FamC phrases, as described by S2, are woven into the sisters' oral exchange in very familiar and informal situations. The FamC as it occurs in the sisters' conversations at this stage is idiolectal and "decorative"; as such it seems to constitute more an effect than a lect. Special phrases from the FC occur, but there is no apparent widespread rule governing independent 
phonological segments that are not part of special FC phrases of the type in (1).

The FamC constitutes in some sense a linguistic system whose rules are dynamic and highly variable and is characterized by idiomatic phrases (as seen in 1), reduced forms, and context-bound deictic expressions (Sapir 1921 , Bernstein 1971; both are taken from Gumperz 1982).

The sisters report that when they have used the FamC with conversation participants who are outside of the immediate family, translations or interpretations for some of the FamC's expressions are necessary (as per Vygotsky 1986, 247; Lotman 1982, 83; 1990, 64). In other words, non-family members are out of the loop of this lect, lacking the background knowledge necessary to interpret many of the FamC variants (see Gumperz 1982, 71), either in their literal/original or their figurative/evolved use. This is typical of family private languages (see Bossard 1945; Malmstrom and Silva 1986; Polisar 1997; see also Vygotsky 1986, 247). Outsiders' difficulty in understanding the code has been in effect beginning at stage IIa.

\section{THE FAX PERIOD}

The fax period (Nov. 28, 1995-Feb. 16, 1996), during the sisters' adulthood, represents a stage intermediate between the FamC (oral) and the SC (e-mail). During this period, S1's e-mail account was not yet established, and S2 could not conveniently access her own account; so the sisters relied on fax as a way to communicate daily while avoiding "telephone tag." When the sisters used the FamC over fax, suddenly this family code-which had previously been sprinkled into their oral discourse-was forced to acquire a graphemic system; that is, faxed messages exchanged between the sisters from November 28, 1995, to February 16, 1996, required some type of spelling convention. However, faxing was much too infrequent (e.g., once or twice daily) for normalization effects to take hold. Because faxes are generally regarded as complete, independent documents (as opposed to e-mail documents, which are often just communication fragments), they show few of the effects typically associated with computer-mediated communication or oral conversations, such as high degrees of informality and emotion. So, in the sisters' brief fax correspondences, the FamC is restricted mostly to opening and closing routines: ${ }^{14}$

2. Listen, sistah ... [...] G's package came in the form of a pick-up slip at the PO. So, I'll go by there in the AM and get it for her. There was a box of checks in the mailbox and could have taken up some of the needed space. [I] So, at 3:3o you'll be major on the brain! Let me know ASA you know!!! I'm getting positive "vives." [I] Sooner or later, [I] E. [I] Sistah [S1, Dec. 1, 1995] 


\section{INVESTIGATION INTO THE E-MAIL CODE}

The fax period ended on February 16, 1996, having lasted about two and a half months; the e-mail period began on January 26, 1996. So, there were 21 days of overlap between the two periods, during which the sisters struggled with setting up their e-mail accounts and finding convenient means to access them during the workday. When the sisters utilized the FamC in e-mail, new stabilizations and extensions arose, as will be discussed in the sections that follow. This marks the emergence of the SC, which is stage $\mathrm{V}$ of the code's development.

To begin the analysis, the number of e-mails between the two sisters was tracked over time, and the frequency of e-mail correspondence charted (figure 1). Tracking the e-mail correspondence in this way shows the frequency of e-mail use by the sisters and the increase in frequency over two months' time.

In the first month or so of e-mail exchange, the density of FamC/SC variants reflected the oral FamC, ${ }^{15}$ and the representation of the code over fax:

3. You didn't say if you want me to forward D's e-mail to you. Be glad to ... just say the wued! [...] Gotta run ... hectic schedule today. [I] Ah-ite. Beh. [I] Your much-better-these-days-but-still-warped... Sistah [S1, Feb. 6, 1996]

4. Well, thank God you finally sent some mail...I failed to get my address (e$\&$ PO) and faxes off of my computer and have nowhere to send anything I wanna say. I asked ya mudda, but so far she hasn't sent. Didn't have my mail

FIGURE 1

Frequency of the Sisters' E-mail Correspondence over Time

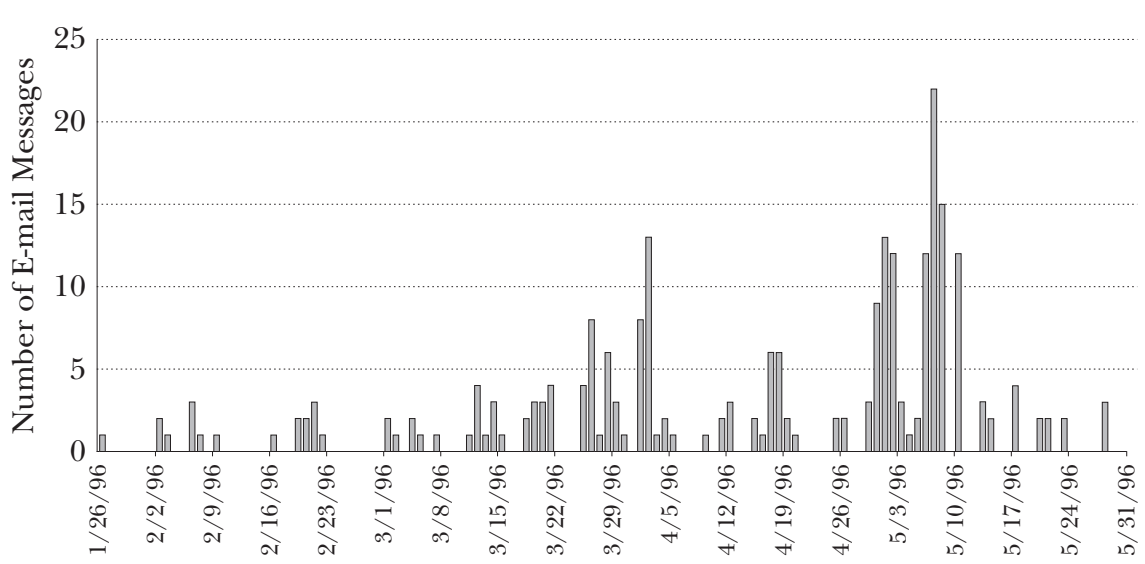


up until Tuesday, anyway. So send me a fax [...] so I'll have ya numba!... Gotta run...gotta prepayah for Wisconsin! [I] Lub, Ya Sistah [S1, Mar. 1, 1996]

5. Teh ya one ting rite now... I'm gonna buy one of those yuppy roll-along luggage tings today; connecters in Michigan and Chicago ... you bet!... Anyway... won't be at the office this week after today; so any mails, faxes, etc won't be responded to til Monday... Let me hear from you today. [I] Ya sistah's gonna get herself a toddy on de plane dis time, teh ya dat rite now! [I] Love, E. [S1, Mar. 5, 1996]

6. Ight! Let's set a time for Sat.-whatcha thank? I could come after aerobics, which would put me there about 3 o'clock, 3:3o la-test. Or better to skip it? Don't know if I communicated correctly, now that I read your msg. [...] Wep. Back to my headache! [S2, Mar. 12, 1996]

By late March, tokens of code are more frequent (approximately 130 per 1 oo lines of text):

7. Hey FIBE!!!!! [I] In uniquely Fibe fashion, I notice you didn't answer my question re: the nail parlor search!!! Well??? [I] I've got more on my plate than I know what to do with: [...] support wib yo daddy [...] yo daddy is one ub dem! [...] support for my buddy and colleague R., the smoking menopausal study?! [...] aerobics. AAAAAAH! [I] bye, my fabe fibe! [ף] LUB! Ya bizzy sista! [I] p.s. no tehhhhhm fa min! [S2, Mar. 29, 1996]

8. Girl, dare's alwa tehhhm fa min ... ya make dat tehhm if ya hab to! [I] Whibe I wuz ansring ya 2nd maeh, I had an application failure, so it was wiped out; didn't hab time to repeat. Still don't hab tehhm to talk.... finally got some excitement!! [I] Beh [I] lub ya! E. [S1, Mar. 29, 1996]

9. a. Hey! Dat was a shote may! Yo daddy didn't raise no quiet youngns, naeho! [I] Have you communicated wib de parental unit yet???? [...] Hab day written you? [S2, Apr. 2, 1996]

b. Ya no, dare ah times when shote maze is betta dan no maze! Ya lucky ya got dat! [S1, Apr. 2, 1996]

There is an increase in frequency of FamC variants that visibly occurs in the documentation after March 26, 1996, as shown in figure 2. In other words, at this point, the density of the code within the e-mail texts begins to increase sharply.

To quantify this increase in code density, the lines of each e-mail message were counted, and the number of SC instances was divided by the number of lines of text of individual e-mails to derive a ratio of SC to non-SC e-mail text. Then a running average ratio of SC to non-SC text was obtained and mapped over the four-month period.

To summarize: When the sisters had been e-mailing each other for about two months (around March 26, 1996), the following two major effects can 
be noted: (1) when e-mail became convenient and easy for the sisters to use, their e-mail use increased, as shown in figure 1; and (2) with the frequency of e-mail exchange, the density of FamC/SC variants increased markedly, as shown in figure 2 .

The combined results of (1) and (2) (figures 1 and 2) indicate that the more frequently the sisters used e-mail, the higher the percentage of code words per message that occurred. Therefore, I have chosen March 26, 1996, as the date demarcating the major transition to a distinct SC.

\section{CHANGES AND THE STRUGGLE FOR NORMS}

After two months of e-mailing, the sisters' FamC/SC variants were still being negotiated for common and frequent lexical items. The similarity of the variant forms may indicate a struggle for some normalization in spelling to reflect pronunciation:

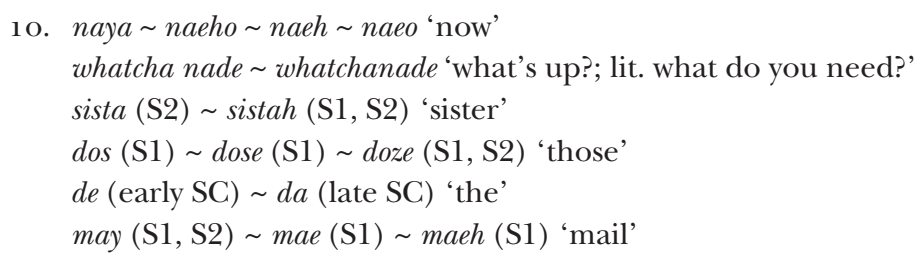

FIGURE 2

Change in Density of the E-mail Sibling Code over Time

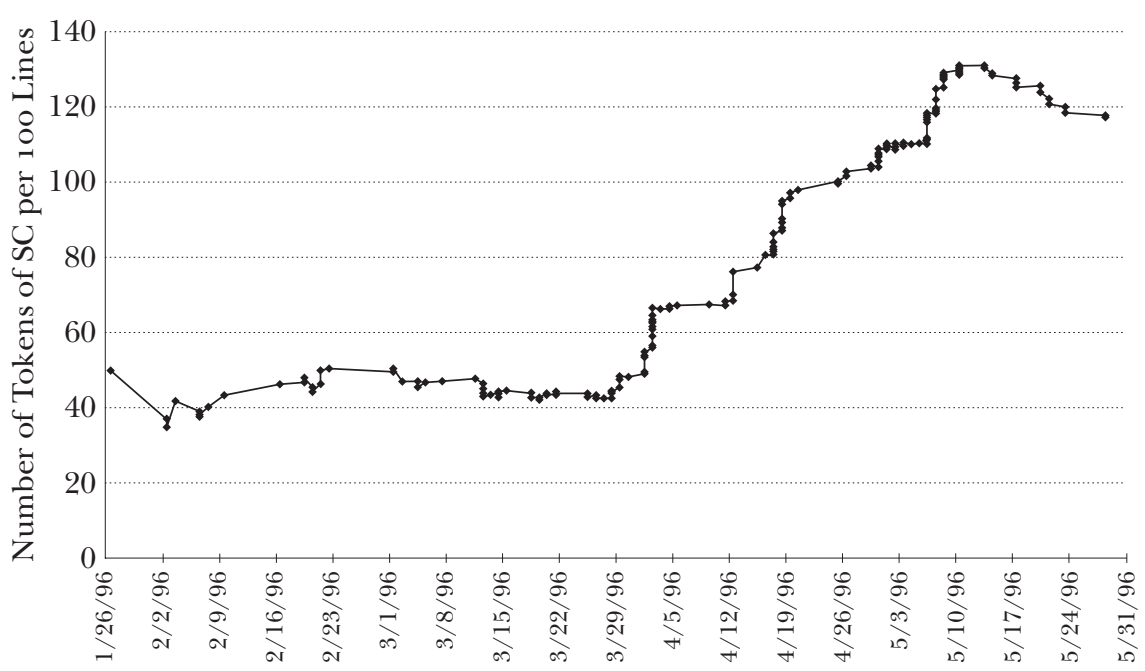


Some definitive shift can be identified in the development of the SC. One type is phonological, such as the generalization of some assimilation rules from the FC. Some shift comes in the form of lexical and morphosyntactic innovations. Other shifts are morphosemantic, such as the decontextualization and subsequent semantic shift of function words and discourse markers.

Table 2 shows rule generalization, through the loss of phonological conditioning rules, in the substitution of stops for continuants from the FC to the FamC/SC. Most SC variants reflect parody of the FC; in the FC, these were conditioned by certain phonetic environments (e.g., word-final and medial $\mathrm{v} \rightarrow \mathrm{b}$, as in love $(i t) \rightarrow l u b(i t))$; in the FamC (oral), these were imitated as closely as possible. In the SC (e-mail), the stop-for-fricative substitution is more fully generalized (e.g., not only medial and final, but also initial $\mathrm{v} \rightarrow \mathrm{b}$, as in very $\rightarrow$ bery).

Some rule generalization seems to affect certain lexemes particularly strongly. The variants for 'your' and 'with', which are particularly vulnerable (perhaps because they are high-frequency words), are shown in table 3. The choice between yo and ya is stabilized to certain lexemes (although the motivation for the choice is unclear). It seems that yo is lexicalized for

TABLE 2

Rule Generalization: Substitution of Stops for Continuants

\begin{tabular}{|c|c|c|}
\hline $\begin{array}{l}\text { Father Code }(F C) \\
{[\mathrm{v}] \rightarrow[\mathrm{b}] \text { word-finally }} \\
\text { before a stop (beleeb dat } \\
\text { 'believe that') }\end{array}$ & $\begin{array}{l}\text { Family Group Code (FamC) } \\
\text { [v] } \rightarrow \text { [b] word-finally } \\
\text { before a stop (beleeb dat } \\
\text { 'believe that') and } \\
\text { between vowels (lub it } \\
\text { 'love it') }\end{array}$ & $\begin{array}{l}\text { Sibling Code (SC) } \\
<\mathrm{v}>\rightarrow<\mathrm{b}>\text { everywhere: } \\
\text { word-initially (beleeb dat } \\
\text { 'believe that', bery 'very'), } \\
\text { intervocalically or between } \\
\text { a vowel and }<\mathrm{r}>\text { (ebolb } \\
\text { 'evolve', lub it 'love it', ebry } \\
\text { 'every'), and word-finally } \\
\text { (I'b 'I've') }\end{array}$ \\
\hline $\begin{array}{l}{[\partial] \rightarrow[\mathrm{d}] \text { word-initially }} \\
(\text { dat }, \text { dis })\end{array}$ & $\begin{array}{l}{[\partial] \rightarrow[\mathrm{d}] \text { word-initially }} \\
(\text { dat, dis }) \text { and word- } \\
\text { finally (wid 'with'); } \\
{[\theta] \rightarrow[\mathrm{t}] \text { word-initially }} \\
\text { (ting 'thing', tink 'think') }\end{array}$ & $\begin{array}{l}<\mathrm{th}>\rightarrow<\mathrm{d}>\text { word-initially } \\
\text { (dis 'this') and word- } \\
\text { finally (wid 'with'); } \\
<\mathrm{th}>\rightarrow<\mathrm{t}>\text { word-initially } \\
\text { (ting 'thing', tink 'think') } \\
\text { (same as FC) }\end{array}$ \\
\hline $\begin{array}{l}{[\mathrm{z}] \rightarrow[\mathrm{d}] \text { restricted to }} \\
\text { the word bidness } \\
\text { 'business' }\end{array}$ & $\begin{array}{l}{[\mathrm{z}] \rightarrow[\mathrm{d}] \text { restricted to }} \\
\text { the word bidness } \\
\text { 'business' (same as } \mathrm{FC} \text { ) }\end{array}$ & $\begin{array}{l}\mathrm{S} 2 \text { only: }<\mathrm{s}>([\mathrm{z}]) \rightarrow[\mathrm{b}] \\
\text { word-finally (ib 'is', wub } \\
\text { 'was'); } \mathrm{S} 1 \text { only: }<\mathrm{l}>\rightarrow[\mathrm{b}] \\
\text { word-finally (whibe 'while') }\end{array}$ \\
\hline
\end{tabular}


TABLE 3

'Your' and 'with'

\begin{tabular}{|c|c|c|}
\hline Father Code (FC) & Sibling Code pre-Apr. 1996 & Sibling Code post-Apr. I996 \\
\hline ULE: $y a$ before $\{\mathrm{a}, \mathrm{e}, \mathrm{C}\}$ & yo ya: ya daddy (S1, 3/13, & ya sista, ya mudda, ya numba \\
\hline a apple, ya egg, ya sista); & $3 / 26) ;$ yo daddy $(\mathrm{S} 2,3 / 1)$ & ya an \\
\hline before $\{\mathrm{o}, \mathrm{u}, \mathrm{C}\}$ (yo only & yo mudda $(\mathrm{S} 1,2$ & yo im \\
\hline le, yo uncle, yo room) & mudda $(\mathrm{S} 2,2 / 3 ; \mathrm{S} 1,3 / 1)$; & RULE: \\
\hline $\begin{array}{l}\text { Phonological } \\
\text { itioning (spoken) }\end{array}$ & $\begin{array}{l}\text { eral); YO sista } \\
\text { SISta (S2, } \\
\text { atic]) }\end{array}$ & $\begin{array}{l}\text { ertain); invoke } y c \\
\text { e }\end{array}$ \\
\hline ith': & wid ( & wib 1 \\
\hline In & wib y & and \\
\hline ib Barry); otherwise wid & Sylvia $\left(\mathrm{S}_{1}, 3 / 12\right)$; wib 'um & RULE: No condition; wib \\
\hline ricol & $\left(\mathrm{S}_{2}, 3\right)$ & 3/29 (S2 \\
\hline & $\left(\mathrm{S}_{2}, 3 / 29\right)$ & the initiator of wib) \\
\hline
\end{tabular}

yo daddy and some other nouns (e.g., yo immuno). By the late SC stage, ya has been generalized for other nouns. The rule for wid wib is at first (FC, FamC, early SC) phonologically conditioned. At some point early in SC, the variants indicate that the morphophonological conditioning rule is lost. In later SC, at the initiation of S1 (Mar. 11, 1996), wib is generalized to other, nonconditioning environments.

\section{SEMANTIC AND MORPHOSYNTACTIC CHANGES}

Shifts in meaning, reference, and usage were definitive. With increasing frequency of use, certain family words and phrases became associated with meanings shared between the sisters:

11. whatcha nade 'what's up?; lit. What do you need?' (initiated by S1 per fax, Dec. 5, 1995)

naeh 'now' (emphatic particle)

yamudda 'lit. your mother'

In the SC's morphosemantic changes, discourse markers are strongly affected-possibly because these are directly linked to family experience. Such discourse structures became more conventionalized, resulting in shifts in semantic nuances and generalizations of usage, as shown in table 4 . The two particles teh ya dat and naeh(o) have both undergone semantic bleaching, 
as described by Eble (1996). This occurs when some words become clichés in the conversational context and, as a result, lose their semantic "punch" (Arlotto 1972, 159) —a grammaticalization-type process which, according to Meillet (1921), is motivated by the expressive function of language. Taken a step further, as Arlotto notes, bleaching can result in the creation of a new category, in which the old word or expression is used in a semantically and syntactically different context, with the result of conglomerate word senses (Vygotsky 1986, 247). And this is precisely what we see with the whatchanade holophrastic particle:

12. [...] Ya wanna just do the bond ting *nex* fri. and kick out outta bed the nex mawnin? Or whatcha nade? ([...] I'm just trying to find out whatchanade.) [S2, May 7, 1996]

TABLE 4

Semantic Changes in Discourse Markers

Father Code (FC)

I'll tell you one tang right

now (emphatic warning);

I'll tell ya dat right now

'One thing is certain'

naeh 'now' (interjection, Same as FC

emphatic, warning,

nontemporal)

\section{Family Group Code (FamC) Sibling Code (SC)}

teh ya one ting (tang) right I teh ya dat ting rite now

now (nonemphatic) ${ }^{\mathrm{a}}$

[morphological blend, with emphasis, but no mark of warning] $\left(\mathrm{S}_{1}, 2 / 21\right)$ teh dat (semantically vacuous; nonwarning; unmarked for emphasis) ${ }^{b}$

Naya/naeh/naeho/naeho [interjection, emphatic, nonwarning, nontemporal] (I) can't b(e)leeb dat, naeh(o)! 'I really can't believe that!' (emphatic with intrusion of naeho particle)

Whatcha need? 'What do you need? Why are you calling? What can I do for you?' (telephone response after the caller has self-identified)
Whatcha nade? 'What's up? Whatchanade? 'What's up?

What's new?' (generalized What's new? What's wrong? greeting for telephone What do you think?' used by the receiver to the (general wh-particle; caller after the caller meaning varies) has self-identified)

a. From closing: “...teh ya one ting rite now...gotta run ..........." (S1, Feb. 19, 1996).

b. "Now yo daddeh gettin his avengement fo all our mess as youngns! Teh dat!" (S2, May 8, 1996). 
13. [...] I just figured we'd be close to C. and wouldn't have to get a late start Sat am. Whatchanade? [S1]

14. Or, you could let yamudda keep babies obernight an' let Axsh bring them in the mawnin. I nade dat a lot betta [...] [S2]

15. Ok, whatchanade. [S2]

The first instance of whatcha nade in (12) and the single instance in (13) show the lexeme's use as a bare interrogative. Here the meaning is clearly not 'What do you need?', but something more along the lines of 'What do you think?' The second instance of whatchanade in (12) shows the nominalization of the $w h$-lexeme. The meaning appears to be the same as the interrogative, but with embedding, 'I'm just trying to find out what you think'. In (14), S2 chooses betta 'better' instead of mo 'more', which indicates that the new meaning of the whatchanade concept (opinion or preference) is preserved, even though the wh-element itself is not present. In other words, nade here means 'like', and cannot mean 'need'. Finally, the use of the marker in (15) with the meaning 'whatever' shows its extended use as a general $w h$-element. The example in (16), provided by S2, shows that the father is not party to the new meaning of the particle; he interprets the wh-phrase literally (FC 'What do you need?') rather than as a greeting (late FamC/SC):

16. S1/S2: Whatcha nade?

Father: I need a lot of things.

Likewise, the reference of the grammatical particles yo/ya underwent a shift in early SC for ya mudda. Originally, according to S2, the father used ya mudda (FC) when speaking to his daughters to refer to their mother, as in $(17)$ :

17. Father: Do what ya mudda says, and hush!

S2 (FamC stage) then transferred the lexeme yamudda to all environments to refer to her mother, whether talking to her father or to her sister, as illustrated in table 5 . That is, the $y a / y o$ identities originally had normal deictic pronoun reference ( ya mudda 'your mother', yo daddy 'your daddy', ya sista ( $h$ ) 'your sister'), after which they were shifted (yamudda 'mother of S1 and S2', yo daddy 'father of S1 and S2', ya sist(h)a 'S1' or 'S2', dis sistah 'I/me, the speaker S1 or S2'.) By "shifted reference" I mean that the pronominals have become opaque, and the entire unit (pronoun + noun) lexicalized, such that they have become referring expressions for specific entities, that is, for the parents of S1, S2, and the sisters themselves (as in 18). In other words, they are no longer deictic, but referential. By the late FamC stage, according to 
TABLE 5

Reference Shift

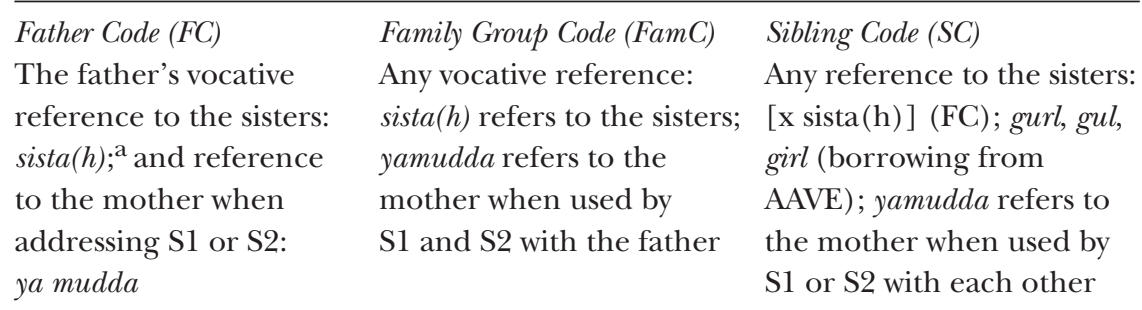

a. According to S2, the father uses the vocative sista( $h)$ to his daughters in the way that some parents use the vocative son or boy to their sons.

S2, the father, the speaker of the FC, makes errors in interpretation when his daughters use elements from the evolving FamC:

18. S2: What was yamudda like as a teenager?

Father: I don't know, I wasn't born yet.

So, in example (18), the father in his interpretation fails to switch the reference of yamudda from 'your mother' to 'Mom'. He clearly believes S2 is referring to his own mother, rather than to his wife and the sisters' mother. In this instance, the father's misinterpretation results from his adherence to the original compositional meaning of the phrase; he is not aware of its new lexicalized interpretation that developed between the two sisters in the FamC stage. The examples in (16) and (18) support the notion that there is an emergent code that has become private to the sisters alone.

In terms of morphosyntactic development, a deictic form dis sistah emerges over e-mail (in the SC). The source is an observation by $\mathrm{S} 1$ about a recent Lois and Clark television episode:

19. Did ya see our [super-] man shrinking da udder night? I was almost in tears when he wasn't sharing his woes wib Lois. You can share ya woes wib dis sistah, Clark!

Here $\mathrm{S} 1$ uses the phrase dis sistah in reference to herself as a separate entity. S1 has apparently construed the phrase ya sista $(h)$ as a lexicalization, subsequently deleted the pronoun and substituted a deictic marker (dis 'this'). The resulting phrase $[x \operatorname{sista}(\mathrm{h})]$ retains its original reference from the phrase ya sista(h), and thus refers to the speaker.

In the course of the code's development, borrowings and neologisms also became more common (see table 6). For the sisters, neologisms appear 
TABLE 6

Borrowings and Neologisms

Father Code (FC)

Few borrowings (from child language):

I hurt mytef!
Few neologisms:

boyfrennin' 'hanging out with a boyfriend'
Family Group Code (FamC)

Lexical borrowings with medial /er/ are quoted directly in entire Archie Bunker phrases: woik 'work', woid 'word' (Don't say dat woid! I come home from woik...) Lexical borrowings (all from AAVE) restricted to certain words: jivin' 'jamming', stayin' 'residing', tell it! 'Amen!' Borrowing from family friend: dot's troo! 'that's true!'

Some neologisms: crahtroo-tunnez 'crawl through tunnels' (innovation), at this point, now, at this point (reduplication of characteristic FC phrase at this point)
Sibling Code (SC)

All borrowings used in FC plus $<$ oi $>$, <oy $>$ spread into other intances of /er/: hoyt 'hurt', hoid 'heard' Lexical borrowings from AAVE: vocative girl, gul Copula borrowing from AAVE: zero copula (you crazeh), "invariant" be (it be a fibe), "movable" -s (I DOES)
More frequent neologisms: immuno-, immuze- 'immunizations'; 9-baby 'youngest child of S1'; fibin' 'lit. fiving; avoiding'

to be a way in which to further the creative "machine" in the code. Indeed, by extending the parody to all forms of grammar, the code is more complete and mirrors canonical language creation, as typically seen in creoles, for example.

\section{THE SHIFTED CODE}

The code variants interwoven in the sisters' conversations, in the course of e-mail correspondence over two to four months' time, came to form some sort of system, albeit an unstable and loosely normed one. The following data occur well after March 26, 1996, the date demarcating the emergence of a recognizable sibling code: 
20. Hey Honey, [I] Thanks for the bonding time (those $6 \mathrm{~s}$ will figure out a way to bond, now, teh dat right naeho!), and esp. for the fibe letter. it was really a help confidence-wise, and I know it took somewhat ub a sacrifice fo a FIBE to write it! Thanks, sista. ! Liked your intro about attitude majustent- that's the perfect intro fo such a talk! really enjo-ad bay-bez. (the only fighting really WUB in de lass fibe minit!). T.S. is prob mo evolbed dan iny 2 I know! she has become "overtly" honest (tough fo tooz!): like, she told me I really needed to wash my hands again to get the bike grease off! I was very impressed! I lubbed it! and de yunga wun is becoming much more sense-ub-huma-ful wib tings she disagree wib) ... wep. tanks fo da tawks. lub dat sista naeho, teh DAT! [I] BEH! lub [I] ya sista [...]! [S2, Apr. ${ }_{15}$, 1996]

21. I meant ta talk to BB bout da childrearin ting, but forgot to. I'll call her. Tanks fo da reminda, I need all ub dose I can get! Yep, joyed the bond'n time. De stained milk was good, too. Tanks! I did hab sum 2nd thoughts bout rebeelin sum ub ma inna-mos taughts in da mae da udda day; but I figga yu ma sistah and ya need hep wib dose fibe tings fo ya korea (-good one, huh?) an I guess it woodunt hoyt when da 2 sistahs run up ona prob. Anyway, I guess one way to figga owt a fibe is to get him/her to anlize anudda fibe (dough it's probly betta not to teh him it be a fibe he's analizin! But cents I'm soooooooo evolved, it's ok fo me! Shoa am glad ya enjoyeed da babeez; day always come...home talkin bowt dare Aunt H.!!!!! Dare already lookin forwud to da nex trip. Keep me posted on da [...] korea front. Peyut wants your "hard" address and I wasn't shoa I rememba'd it, so ya might wanna may him de street numba an all dat. [I] Take cayuh! Lub [...] ma Sistah!!!!!!!!!!!!!!!!! [I] Beh [S1]

22. Que ese "UB"? [I] Mom is going at dis ting wib mo zest dan anyting I'b seen in a lawng time, gul. Personally, I can lib wibout goin and I AM tinking bout flying Valuejet, so I don't hab to be in de cah so long and put up wib all dat whinin fo 2 days up dare and 2 days back! Plus, we'll be too crowded... (Dat did it... enuff sehd!) [I] Lub, [I] Da fattest fibe ya know, gul! [S1, Apr. 26, 1996]

By the fourth month of e-mail correspondence, the SC seems to be fully integrated into the sisters' e-mail conversations, as seen in the sequence of messages in (23):

23. a. I had in mind dat we would sistah-bond ova dinna while W. is dribin to get girls. Dat would gib us probably $3+$ hours. Whatchanade? I would gib ya exampas ub tings we could go in dat time but I'll leeb dat up to you! Dinna site is yo choice (cep fa Jacques')! Let's just ask Mom whether she wants to do cold plate smorgasborg(sp) or outside Lizbeh's. Both sound good to me! [S1, May 7, 1996] 
b. Or, you could let yamudda keep babies obernight an' let W. bring them in the mawnin. I nade dat a lot betta. [I] Ya [...] SISTA! [S2]

c. Whatchanade? Da babeez will go to sleep shortly after arrival; or, if not, W. can entertain them... Whatchanade? [S1]

d. Wait a minute. Can W. not just bring them sat. a.m. at whatever time y'all would leave anyway? Besides, that would let them bond wid ya mudda an yo daddy. It would also solve the who-sleeps-wid-who problem. I KNOW you're not having a detwining problem! [I] Whatchanade about this playan? [I] Better-here? [I] Better there? [I] H. [S2]

e. [...] I can lib wib whatever. We'll definitely make da most ub da bonding time. You and I can eben go fa breakfass Sat am by oursef. Whatchanade? [S1]

f. Ok, whatcha nade. [I] I should expect you at 6 then? [I] lub [I] sista [S2]

This stage V code remains, according to the sisters, chiefly e-mail-bound, with almost no carryover into their spoken conversation.

\section{CONTEXT}

Clearly, domain and context determine when, whether, and to what degree a code appears. In this corpus, the use of the SC seems to be determined by the effects of the e-mail medium, as well as by topic of conversation (triggers). More generally, the context of the family and sibling relationships themselves provide the backdrop for code usage and development, particularly when these recall earlier family or childhood experiences (such as with the father's idiomatic "child-rearing" expressions). Ultimately, the context of the conversational exchanges is found directly and unequivocally to affect the extent of use of the FamC/SC over e-mail.

In the sisters' e-mails, personalized statements far outnumber objective factual ones. Not surprisingly, they usually render highly personalized statements in the SC:

24. a. DOT's TROO! rememba girl: she don't git mad when ya don't respond RIGHT- she jes git mad when ya don't respon! (ie, when you fibin'!) BUT I did tink about de T.S. ting: It really WILL make her happy if you tell her that T.S.'s been wanting to do things... she'll like DAT, naeo! Plus, you probably now could "check in" wib her just to see whatcha nade. remember dat 2's don't HAVE to be in control (dat's 8's)—day just have to KNOW (in general, naeo, in GENERAL!). [S2, Apr. 2, 1996]

b. Web, my "lunch-time" is ober... See ya soon. T.S. wants me to ask you if they can come spend the Sat nite after this (the 13 $3^{\text {th }) . ~ I ~ d o n ' t ~ t i n k ~ i t ' s ~}$ 
for any special date; she just asked when they could spend wib Aunt $\mathrm{H}$. again and I said, "When do you want to." So she came up wib dat day. Just let me know if their playuns hab bin chainged. [S1]

In accordance with Gumperz's observations (1982, 8o-81), the two sisters, in their e-mail correspondence, tend to render objective factual statements ("informational purpose," Chafe 1985) in standard English, depending on the degree of objectivity called for in each situation:

25. Are you drawing parallels between you and Emily? If so, I think it's only temporary. So you don't like parties. [...] But, I've been wrong before (not often!) [S1, Apr. 17, 1996]

Interestingly, "heated" and highly serious topics are, like some of the sisters' objective factual discussions, carried out in standard English and excluded from the SC domain; this reflects not only the "entertainment value" of the SC (and of much of e-mail in general), but also the phenomena of divergence and social distancing:

26. a. I don't mind if you quote me, but if you do, please quote me accurately [...] [S2, May 20, 1996]

b. I did not intend to misquote you. I thought I checked each message before I " ". [S1]

However, some carryover from the SC is evident in the sisters' moderately serious discussions:

27. a. L. has been o-o-t @ a conference (which I knew), and A. wanted (as you know) to "proof" [...] before I gave L. his copy. So I only just gave L. his yesterday. I've promised A. to get back to him (A.) tomorrow to check. To contact L. now would mean e-mail (no waiy) or telephone (no waiy in $\mathrm{H}$ !); so I'm having [...] mtgs. wib L. [...] very soon to discuss my memo and ideas. will hear tomorrow what A. has to report. BEH! gotta run!...[I] ya S! [S2, Apr. 3o, 1996]

b. [...] Sounds like your ducks are in a good row re: L. Just don't let him hide OOT too long! NO MORE E-mails, TELEPHONE CALLS OR UDDER NON-FACIAL COMMUNICATION TO DAT FIBE! (Dis fibe is addicted and feels as dough she gets da emotional message across as intended; no?)... [I] Beh [S1]

Interestingly, the SC was easily adaptable for the two conversants in their email discussion of technical topics, a domain where technical jargon might typically be invoked. The sisters report that the FamC/SC would not have been used in the following long excursus if the conversation had been oral: 
28. Da stupud ting bout da beurocracy is dat da organization doesn't make sense half da time. Here goes about dis ting: [I] ] -D. is a Department of da Gov't... [I] -Two ub da Divisions under D. are E. and M. [I] -C. is a Section withing E.: N. was a Branch unda C. until 2 years ago when it became a Section in its own right... [I] -Part of N's responsibilities is dealing wib... STD ... [I] -C. deals wib da udda diseases [I] -Day should be under the same Division...N. doesn't have a Surveillance Branch and relies on C. for statistical surveillance. It's a mess, gul! [I] -Dare's some hush-hush talk bout moobin N. back to E., but who knows? I don't tink dey want to moob back now (fa raisins I won't say...!) [I] Anyway, dats da first class ub D. 101. [S1, Apr. 26, 1996]

Further, the sisters' ostensibly conscious efforts to match each others' styles results in maximized style convergence, as seen especially in the contiguous message interchanges. In such examples of metalinguistic cooperation, we can see that the density of one sister's SC-to-non-SC text results in a matching density of SC to non-SC text by the other sister. Similarly, individual variants (spelling and lexical choice) are frequently matched. Here, S2 initiates the form plaistic; $\mathrm{S} 1$ uses it subsequently, even though she did not use it in her initial e-mail:

29. a. [...] Just be selective in your shoe purchases! Buy them wider and softer if you can and absolutely NO PLASTIC SHOES! [S1, May 2, 1996]

b. [...] I "did not know that" about the plaistic—whatcha nade? [I] I DOES buy soff nonfemalest of the female shoes, dough (you saw de ones I bought wichour caad.!) [I] Whatcha nade about plaistic? [S2]

c. [...] Plaistic shoes gib bout as much as ya tight hatband, gul; tink bout it. [S1]

In fact, S2 initiates the use of the full-fledged SC in this exchange, to which $\mathrm{S} 1$ responds in kind. That is, $\mathrm{S} 1$ 's initial message contained no SC; but when $\mathrm{S} 2$ replies with an all-SC e-mail, S1 responds in kind-in full SC mode.

\section{SUMMARY AND CONCLUSION}

FREQUENCY IN THE COMMUNICATION. In considering the development of the code, it is important to note that the sisters' e-mail communication itself is very frequent (several times daily, as noted in figure 1 ). Additionally, specific surface features (as discussed in tables 2-6) in the sisters' code appear to be fairly repetitive. These phenomena in tandem explain in part why the e-mail version of the code is structurally quite fully developed, particularly in that high repetition and frequency of use are long known to solidify and stabilize surface linguistic structures. 
DENSITY OF THE CODE. The change in density of code (i.e., the shift in balance of code and noncode elements) reflects its status as an emerging variety. The code density in the sisters' e-mail increased over time: over the course of the four months of e-mail communication, the code gradually began to permeate the messages. This included not only messages on casual topics, but also, notably, the code eventually attained functionality across a wider range of topics and domains, indicating the emergence of a robust code.

E-MAIL'S EFFECTS ON THE LINGUISTIC FORM. The sisters' code was used more haphazardly in its oral form (particularly in its inception as a family code), and the code did not achieve a robust form until its expression and expansion over e-mail. In the e-mail environment, rapid, and in some cases drastic, changes occurred in the linguistic form of the code. One factor appears to be the social capacity of e-mail to tighten loose bonds and to help to rigorously develop and extend surface realizations and rituals more fully. This capacity is clearly evident in the message content and is also reflected in the social and linguistic development of the sisters' code.

This development of the private language did not proceed blindly; on the contrary, the code's form and development was self-consciously realized, most notably so in the e-mail environment. It is clear that this is in part a direct result of the physical and psychological features of e-mail.

In terms of the physical, first and foremost, e-mail is a written mode, which automatically means that it is self-reflective; this effect is augmented by the built in "quote" ("include previous message") feature. Furthermore, the high potential for persistence of every utterance (unlike Instant Messaging and Internet Relay Chat, for example) provides for a ripe visual environment for planned, self-conscious expression to occur in its most deliberate form. Other, apparently oppositional features, act complementarily to optimize the environment for play and change. Notably, the rapid turnaround time (in opposition to built-in lag time) keeps the topics and new forms fresh, allowing for frequent repetitive use, which in turn more readily allows for change. Lag time, for its part, allows for high metalingual activity and thoughtful, creative self-expression. Together, an optimal environment for both nonconscious and self-conscious language creation is enabled.

In terms of the psychological, the open and generally informal nature of e-mail as prevalent in e-mail "culture" allows for the intrusion of unfettered and unchecked creativity, which is often linked with nonconscious activity. On the metalingual side, e-mail's status as a "fun" medium invites the deliberate use of creative humorous expression for self-entertainment.

It seems that the hybrid nature of e-mail, as fostering both self-reflectivity and spontaneous expression, allows private language, such as that of the 
sisters in this study, to so readily emerge and to mutate. For the stabilization of this particular code, expression over the e-mail medium was crucial.

METALINGUAL ACTIVITY AND ITS EFFECT ON LANGUAGE FORMATION AND CHANGE. Self-consciousness seems to be a prerequisite for robust private language development. Ultimately, heightened metalingual activity is one important common thread uniting e-mail (as a domain) and private language (as a variety). This commonality resulted, in the present case, in an optimal confluence of features which fomented rapid and in some cases essentially "quantum leap" linguistic changes. Ultimately, e-mail's particular brand of hybridity (in terms of the particulars of its physical and psychological features) renders it a medium par excellence for private language construction.

This leads to the question of how quickly and dramatically any given language variety could potentially undergo change in other "extreme" environments, when all factors are optimized, particularly in complementary interaction and when metalingual activity is at a maximum. Only further investigation can settle this question-an important one indeed for the nature of language and language change.

\section{NOTES}

I am grateful to the anonymous reviewers and the American Speech editors who helped me to shape the focus of the final version of this paper.

1. This feature is not stable in synchronous Internet Relay Chat and Instant Messaging, which are in many respects more akin to spoken language. In these types of synchronous texting, by contrast, previous responses eventually disappear, scrolling "upward" and becoming inaccessible to the user as the user formulates responses.

2. Crystal $(2001,155)$ discusses the nature of lag time in Internet chat as contributing to a "disruption" of an "already ... complex interaction." While this can also apply to e-mail, my results indicate that e-mail also has the potential to use lag time to the advantage of play.

3. Crystal $\left(2001,4^{1}\right)$ also points out the relationship between informality and language play.

4. Humor as a facilitator of language variation is a force that should naturally be considered (see, e.g., Baym 1995; Houghton 1968).

5. There are two primary competing definitions for "private language." For Wittgenstein (1953), private language refers to language expressed to oneself; this is termed "inner speech" by Vygotsky (1986), who draws a distinction between "language shared by intimates" and "language for oneself." Thus, it is Vygotsky's terminology which will be invoked here. 
6. By "abbreviated,"Vygotsky $(1986,238)$ refers primarily to syntactic and semantic ellipsis, which can occur when contextual information is redundant.

7. For Lotman $(1982,83)$, "intimate" in this context mainly means "familiar"; but the overall agreement with the claims about the nature of intimate speech still obtains.

8. This is along the lines of the Bakhtinian $(1986,69)$ notion of utterance chains, which link interactants to the totality of their shared speech acts.

9. The area of study called "family discourse," by contrast, is usually restricted to purely sociological studies on family dynamics and relationship structures, and the linguistic extent of their analyses is accordingly minimal. The present article is less interested in the sociology of family dynamics than in the mechanics of private language formation and development as it occurs between intimates, particularly in familial relations.

10. By way of background, I am personally well acquainted with both sisters. When they made me aware of the playful nature of their e-mail communication, I asked their permission to examine and use their e-mail messages for this study, with the usual provision of anonymity.

11. In Morrowton there are apparently three class-based regional varieties in the white population: rural, city, and "high-society"/upper-class varieties. Most of the variation is reflected in phonetic detail, as in Saturday: [sæ:d'di] (rural), [sæudi] (city), [særədi] (upper class). Other differences are lexical, such as the use of ain't and double negation.

12. At this stage, the best comparison may be to Tannen's (1984) example of "campy" behavior (an exaggerated style for humorous effect), where one of her informants in a dinner conversation occasionally lapses into a "Jewish mother" routine with no break in the conversational flow.

13. The family friend's performance code was based on the performance code of his college roommate, which was a parody of an African American cook that the roommate was fond of.

14. S2 kept personal faxes from friends and relatives, regarding them as personal letters on a par with U.S. Post-mailed handwritten letters, and provided these to me as examples for use in this study. I have replaced sensitive, extraneous, or overlong material with [...]; line breaks are indicated with [I] ].

15. I have used oral speech examples and other observations about the oral code that were provided by $\mathrm{S} 2$ via personal communications. I do not have recorded oral data for this code. Thus, the oral examples and observations from S2 are anecdotal and serve only as a reference point (chronologically and linguistically) for the object of this study, the e-mail code. 


\section{REFERENCES}

Arlotto, Anthony. 1972. Introduction to Historical Linguistics. Boston: Houghton Mifflin.

Bakhtin, M. М. (M. М. Бахтин). 1986. Speech Genres and Other Late Essays. Ed. Caryl Emerson and Michael Holquist. Trans. Vern W. McGee. Austin: Univ. of Texas Press. Trans. of Эстетика словесного творчества. Moscow: Искусство, 1979 .

Baym, Nancy K. 1995. "The Performance of Humor in Computer-Mediated Communication." Journal of Computer-Mediated Communication 1.2. http://jcmc.indiana. edu/volı/issue2/baym.html (accessed July 16, 2006).

Bernstein, Basil. 1971. Class, Codes, and Control. Vol. 1, Theoretical Studies towards a Sociology of Language. London: Routledge and K. Paul.

Bossard, James H.S. 1945. "Family Modes of Expression." American Sociological Review 10: $226-37$.

Cazden, Courtney B. 1976. "Play with Language and Meta-linguistic Awareness: One Dimension of Language Experience." In Play: Its Role and Development and Evolution, ed.Jerome S. Bruner, Alison Jolly, and Kathy Sylva, 6o3-8. Harmondsworth, U.K.: Penguin.

Chafe, Wallace L. 1985. "Linguistic Differences Produced by Differences between Speaking and Writing." In Literacy, Language, and Learning: The Nature and Consequences of Reading and Writing, ed. David R. Olson, Nancy Torrance, and Angela Hildyard, $105^{-23}$. Cambridge: Cambridge Univ. Press.

Cho, Natasha. 1996. "Linguistic Features of Electronic Mail: Results from a Pilot Study." Paper presented at the Australia and New Zealand Communication Association Annual Conference, Brisbane, July 1 1-13. To be published in ComputerMediated Conversation, ed. Susan C. Herring. Creskill, N.J.: Hampton Press.

Crystal, David. 2001. Language and the Internet. Cambridge: Cambridge Univ. Press.

Danielewicz, Jane M., Dwight L. Rogers, and George Noblit. 1996. "Children's Discourse Patterns and Power Relations in Teacher-led and Child-led Sharing Time." International Journal of Qualitative Studies in Education 9: 311-31.

Eble, Connie. 1996. Slang and Sociability: In-group Language among College Students. Chapel Hill: Univ. of North Carolina Press.

Ferrara, Kathleen, Hans Brunner, and Greg Whittemore. 1991. "Interactive Written Discourse as an Emergent Register." Written Communication 8: 8-34.

Gumperz, John J. 1982. Discourse Strategies. Cambridge: Cambridge Univ. Press.

Houghton, Donald E. 1968. "Humor as a Factor in Language Change." English Journal 57: $1178-81,1186$.

Lotman, Yury M. (Юрий М. Лотман). 1982. "The Text and the Structure of Its Audience." Trans. Ann Shukman. New Literary History 14: 81-87. Trans. of "Текст и структура аудитории." Труды по знаковым системам 9 (1977): 55-61.

. 1990. Universe of the Mind: A Semiotic Theory of Culture. Trans. by Ann Shukman. London: Tauris. 
Malmstrom, Patricia M., and Marilyn N. Silva. 1986. "Twin Talk: Manifestations of Twin Status in the Speech of Toddlers." Journal of Child Language 13: 293-304.

Meillet, Antoine. 1921. Linguistique historique et linguistique générale. Collection linguistique, Société de Linguistique de Paris 8. Paris: Champion.

Polisar, Donna. 1997. "The Private Language of Families: Bringing Us News of Ourselves." Ph.D. diss., Univ. of Southern California.

Rowe, Charley. 2001. "Genesis and Evolution of an Email Sibling Code." Ph.D. diss., Univ. of North Carolina at Chapel Hill.

Sapir, Edward. 1921. Language: An Introduction to the Study of Speech. New York: Harcourt, Brace and Company.

Sebeok, Thomas A. 1991. A Sign Is Just a Sign. Bloomington: Indiana Univ. Press.

Tannen, Deborah. 1984. Conversational Style: Analyzing Talk among Friends. Norwood, N.J.: Ablex.

Voloshinov, V. N. (В. Н. Волошинов). 1976. "Discourse in Life and Discourse in Art." In Freudianism: A Marxist Critique, ed. I. R. Titunik and Neal Bruss, trans. I. R. Titunik, 93-1 16. New York: Academic Press. Trans. of "Слово в жизни и слово в поэзии." Звезда 6 (1926): 244-67.

Vygotsky, Lev (Лев Выготский). 1986. Thought and Language. Trans. newly rev. and ed. Alex Kozulin. Cambridge, Mass.: MIT Press. Trans. of Мышление и речь. Moscow: Соцэкгиз, 1934.

Wittgenstein, Ludwig. 1953. Philosophical Investigations / Philosophische Untersuchungen. Trans. G. E. M. Anscombe. Oxford: Blackwell. 
Copyright of American Speech is the property of Duke University Press and its content may not be copied or emailed to multiple sites or posted to a listserv without the copyright holder's express written permission. However, users may print, download, or email articles for individual use. 